\title{
Measurement of Interconnecting Network for Roadside Unit Placement on Cellular Network to Support Intelligent Transportation System
}

\author{
Okkie Puspitorini ${ }^{1, *}$, Nuradi Siswandari ${ }^{2}$, Ari Wijayanti $^{3}$, Haniah Mahmudah $^{4}$ \\ ${ }^{1}$ Antenna and Propagation Laboratory \\ Electronic Engineering Polytechnic Institute of Surabaya (Surabaya, Indonesia) \\ ${ }^{2}$ Antenna and Propagation Laboratory \\ Electronic Engineering Polytechnic Institute of Surabaya (Surabaya, Indonesia) \\ 3 Antenna and Propagation Laboratory \\ Electronic Engineering Polytechnic Institute of Surabaya (Surabaya, Indonesia) \\ ${ }^{4}$ Antenna and Propagation Laboratory \\ Electronic Engineering Polytechnic Institute of Surabaya (Surabaya, Indonesia) \\ *Corresponding author's email: Okkie [AT] pens.ac.id
}

\begin{abstract}
The significant problems in metropolitan's traffic are road congestion and safety The Intelligent Transportation Systems (ITS) offer improvement for the problems using Roadside Unit placement along the road to detect and inform all matters relating to traffic condition. This research will be conducted measurement interconnection network that will be used by Roadside Unit (RSU) to communicate with the central office. RSU will transmit data type of vehicle and speed information to the central office server. Measurements carried out on the existing cellular network and find the right position for placement of RSU according network availability by considering the received signal power, pathloss and performance data delivery. Measurement locations in the main road metropolitan city of Surabaya by using sensors (counted mode) as the RSU. From the measurements taken showed that communication between infrastructures managed by using digital sensors falcon plus II with a percentage error of less than 3\%. Communications between the RSU and the central office using GPRS / GSM network supported by the presence of a nearby BTS tower. The power level of BTS antenna greater than wireless modem (SIM 900) sensitivity (-107 dbm), with pathloss exponent about 2.77. The ability of data transmission by wireless modem (SIM 900) reached 85.6 Kbps to $42.8 \mathrm{Kbps}$ for downlink and uplink. The server side using the internet network 512 Mbps with a dynamic public IP features that support port forwarding that is useful for data communication. Best sensor position for mounting the sensor horizontally at a height of 40-120 cm from ground level to the maximum detection distance of $150 \mathrm{~m}$ for vertical mounting above the overpass. Best sensor position facing the one lane road with a height of 5-6 $\mathrm{m}$ from ground level, with the best angle measurement is $45^{\circ}-60^{\circ}$ for vertical and horizontal mounting. Average speed of vehicles is $38.34 \mathrm{~km} / \mathrm{h}$ with a volume of 4128 units of vehicles, mostly motorcycles and traffic density 135 units / $\mathrm{km}$.
\end{abstract}

Keywords - Roadside unit, I2I, ITS, cellular network

\section{INTRODUCTION}

Intelligent Transportation Systems (ITS) is a technology that was introduced on the vehicle and the road which aims to improve traffic safety, energy efficiency and the environment. Intelligent Transportation Systems (ITS) is an advanced application that consists of several technologies such as computers, sensors, control, communications, and electronic devices installed in the vehicle and on the road in or der to be able to communicate with each other. ITS devices installed in the vehicle and the roadside to collect information on road conditions such as traffic speed, , congestion, traffic volume etc. This system involves a vehicle, passenger, road operators whom interact among others and engage existing infrastructure systems. Therefore, it needs the integration of technology with wireless communication systems that will improve the quality and reliability of infrastructure's information or Infrastructure to infrastructure (I2I), or vehicle to 
Infrastructure (V2I). I2I Communication system relies heavily on the availability of the network, therefore required selection of the right wireless communication system and proper placement of the sensor as well.

There have been many studies conducted related to wireless communication in ITS communication. K. Kishimoto et al [1] discusses the communication system I2V / V2I, I2I and vehicle-to-vehicle (V2V) in the band $700 \mathrm{MHz}$ band. M. Shahid et al [2] conducted a survey of multiple access technologies such as 802.11p standard, Cellular System, CALM, MBWA, WiMAX, etc. that can be used to support ITS applications. Baber Aslam et al [3] present two different optimization methods for placement of a limited number of RSUs in an urban region. P.Belanovi et all [4] study about some Wireless Links technology for Vehicle-to-Infrastructure (V2I) communications. Nuradi et al [5] have done a preliminary study to measure the power level of mobile communication systems to determine the condition of the environment to support the implementation of ITS in Surabaya. This paper focuses on measurement the availability of cellular network along road to support the roadside unit performance for I2I communication network especially in Surabaya's road behavior. The measurement results in the form of information about the power level of signal reception areas measured, the ability of the network to transmit data to the server and process the most optimal sensor installation.

This paper is organized as follows, Section 1, Introduction of the research describe the background why the measurement conduct and several previous research in many region, Section 2 describes system design for I2I communication. In this section, the design will be present clearly design will be explained clearly include hardware and software requirement to be prepared for the system to run optimal. The next is measurement of available network at Section 3. In section 4 will discuss the sensors used and their installation in RSU, section to 5 will explain the measurement of network interconnection between the RSU and the location of the head office where the servers are located. Finally is concluding the paper.

\section{THE DESIGN OF COMMUNICATION SYSTEM I2I}

The communication system to support Infrastructure to Infrastructure (I2I) has been designed in several stages as follow

\section{Initialize Wireless Modem}

In the initialization process is performed Wireless Modem (Sim 900) is used, by accessing the static IP address that is already configured on the PC server, and initialize the GPRS network of the telecom operator used. Access is opened using port forwarding through Transmission Control Protocol (TCP) so that Wireless Modem (Client) can be connected to a PC (Server) and Wireless modem can transmit data to a PC.

\section{Infrastructure Installation (Client) of the Road}

Infrastructure in the installation process is to install the sensor counter the number of motor vehicles with a microcontroller and a wireless modem. Infrastructure (Client / sensor) is placed on a highway with distance and a predetermined position. The capture process performed by the sensor automatically and in real time within the prescribed period

\section{Process Data Collection (Server)}

Capturing data on the number of motor vehicles in a way that captures the signal back to the traffic sensor detection. Furthermore, the raw data is passed microcontroller to be sent to the server by a wireless modem. On the side of the data is processed using the AVR microcontroller technology so that data can be sent and read side server

\section{Calculation of Link Budget}

In this process will be carried out comparing the measurement data communication between infrastructure quality in cellular networks with theoretical calculations of the Link Budget. At this process we will get the information about the state of the density of roads and communication systems existing network.

\section{Process Data Visualization}

The data obtained is displayed in the form of a Graphical User Interface (GUI) with Software Visual Basic.

\section{Data Analysis}

From the data communication between the planning of infrastructure through cellular networks will be obtained information about the quality of the communication network on the highway and supporting data obtained by an analysis of traffic conditions along the road in the city of Surabaya.

Based on all the stages which have been described previously, the design of the system can be illustrated in Figure 1 


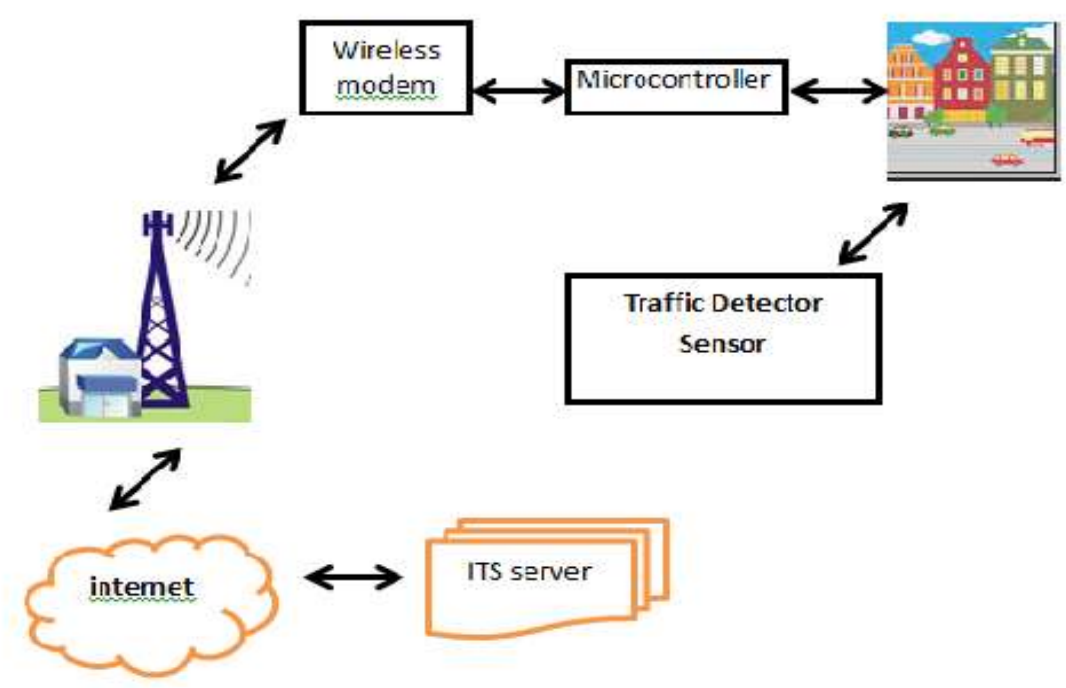

Figure 1: Desain of Communication system for I2I

To be able to implement the system design as it has been designed in figure 1, the necessary hardware and software according to the requirement of the system. The system requirement for I2I communications systems including the specifications outlined in table 1

Table 1: I2I communication system requirement

\begin{tabular}{|c|c|c|c|}
\hline No & Name & Specification & Volume \\
\hline 1. & Power Supply & - 9V DC dan $18 \mathrm{~V}$ DC & 1 \\
\hline 2. & $\begin{array}{l}\text { Vehicle } \\
\text { Detection } \\
\text { Sensor }\end{array}$ & $\begin{array}{l}\text {-Frequency K-Band(24.125 GHz) } \\
\text {-DB-9 connector } \\
\text {-Interface serial RS232 }\end{array}$ & 1 \\
\hline 3. & Batteray & $5200 \mathrm{Ma}, 11 \mathrm{~V}$ & 1 \\
\hline 4. & USB Adapter & $\begin{array}{l}\text {-Penghubung Supply PLN dan } \\
\text { sensor }\end{array}$ & 1 \\
\hline 5. & $\begin{array}{l}\text { Microcontroller } \\
\text { ATMEGA } 162\end{array}$ & $\begin{array}{l}\text { - } 2 \text { serial port } \\
\text { - } 5 \text { port I/O } \\
\text { - SRAM Capacity } 1 \mathrm{~Kb} \\
\end{array}$ & 1 \\
\hline 6. & $\begin{array}{l}\text { Wireless } \\
\text { Modem } \\
\text { SIM } 900\end{array}$ & $\begin{array}{l}\text {-Support Voice, Data, SMS, } \\
\text { GPRS,GSM } \\
\text {-Open AT capable for embedded } \\
\text { applications } \\
\text {-RS232 Serial Interface }\end{array}$ & 1 \\
\hline 7. & $\begin{array}{l}\text { Internet } \\
\text { Provider } \\
\text { (speedy) }\end{array}$ & -Unlimited Packet & 1 \\
\hline 8. & PC/Laptop & $\begin{array}{l}\text {-Windows Vista } \\
\text {-Support OS: } \\
\text { Hyperterminal } \\
\text { AVR Code Vision } \\
\text { Extreme Burner } \\
\text { Visual Basic } 6 \\
\text { Matlab } 10 \\
\text { Speedy Software } \\
\end{array}$ & 1 \\
\hline
\end{tabular}

In planning the selected communications network providers that have the largest and the widest range of services. Under these conditions, an option speedy internet network to pass data among infrastructures . Selection of a wireless modem based on its ability to connect with the widest and most communication networks along the path that will put the sensor. For the choice of sensor based on the requirements that must be served in this case the sensor with the above specifications are able to work according to the requirements 


\section{NETWORK AVAILABILITY}

After all the data needed requirements are known, then the next step is setting up a communication network. This section will discuss the measurement of the availability of the mobile network. In the first phase will be mapping the location of measurements, then measuring the pathloss.For more details then the explanation is as follows:

\subsection{Measurement of Cellular Network Frequency Spectrum}

The communication system between ITS infrastructure requires mobile network. To know the type of telecom operators that can support ITS communications systems necessary to measure the signal. In the mobile network signal measurement is used a measuring tool Rohde and Schwartz Horn Antenna 1-3 GHz of measurement frequency range (800-2200 MHz), which is associated with a spectrum analyzer and a laptop application installed FSH View, so that the results can be seen from the spectrum analyzer and stored on the hard drive of the laptop. The example of measurement results as shown in Figure 2 (800-1000 MHz)

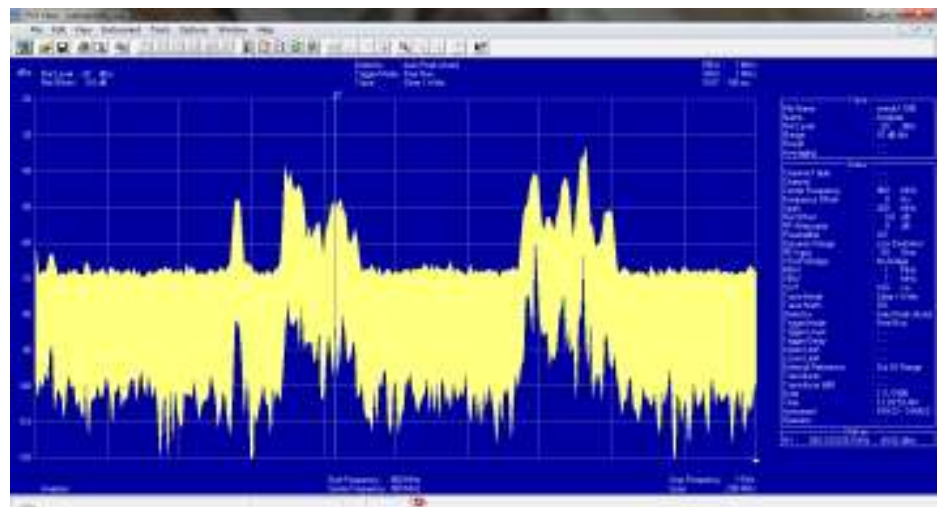

Figure 2: The frequency spectrum of the signal at FSH View $(800-1000 \mathrm{MHz})$

From the window of FSH View (Figure 2 ) can be known spectrum of the signal that appears and power level. To know the telecom operators who have a good performance measurement area can be seen from the power level of each telecom operator in Indonesia which are at different frequency range. Power level used to determine how much BTS antenna transmit power, and matched with the value of the receiver sensitivity ( Rx Sens )of the modem antenna (SIM 900). If the value of Rx Sens antenna is smaller than Transmit power (PTx) then communication can run well.

Base on the measurement signal with a spectrum analyzer and data corresponding Indonesia frequency allocation table [6], the result is that there are several telecom operators in the nearest BTS which operates in the frequency range specified that supports communication between infrastructure ITS such as Indosat, XL, Telkomsel and Axis, so that the user can freely use type of SIM Card for Wireless modem (SIM 900) in accordance with the telecom operators operating in the frequency range that has been analyzed as Table 2

Table 2: Signal frequency measurement results at $800-900 \mathrm{MHz}$

\begin{tabular}{|c|c|c|}
\hline \multicolumn{3}{|c|}{ Range Frequency 800-900 MHz } \\
\hline Frequency (MHz) & Ref Level(dbm) & Telecommunication Operator \\
\hline 870.67 & -40.10 & Telkom Flexi, Bakrie Telecom \\
\hline 873.33 & $-4 ., 02$ & Telkom Flexi, Bakrie Telecom \\
\hline 876 & -55.12 & Bakrie Telecom \\
\hline 878.67 & -54 & Telkom Flexi, Bakrie Telecom \\
\hline 882.67 & -48.52 & Indosat Star one, Mobile 8 \\
\hline $88 ., 67$ & -47.72 & Indosat Star one, Mobile 8 \\
\hline 886 & -51.92 & Indosat Star one, Mobile 8 \\
\hline 888.67 & -48.52 & Indosat Star one, Mobile 8 \\
\hline 936.67 & -43.79 & Indosat \\
\hline 937.33 & -40.43 & Indosat \\
\hline 938.67 & -52.78 & Indosat \\
\hline 942 & -41.78 & Indosat \\
\hline 947.33 & -36.02 & Telkomsel \\
\hline 951,33 & -33.15 & Telkomsel \\
\hline 952.67 & -54.92 & $\mathrm{XL}$ \\
\hline 954.67 & -50.85 & $\mathrm{XL}$ \\
\hline 959.33 & -49.73 & $\mathrm{XL}$ \\
\hline
\end{tabular}


Based on the results of measurements are written in table 2 can be seen that the telecom operator Telkomsel has received the greatest power value is $-36.02 \mathrm{dbm}$ at $947.33 \mathrm{MHz}$, the operator Telkomsel has the greatest level of signal reception compared to other operators.

In addition to the frequency range, the power level / sensitivity was also observed. Rated output power level of the operator at a BTS antenna must be greater than the sensitivity of a wireless RF modem (SIM 900) which has a value of $107 \mathrm{dbm}$. Based on the measurement results obtained all the operators have received power value greater than the value of the received power wireless modem. Therefore, the measurement results of each operator compared and found that the greatest value is the value of the operator Telkomsel. Based on the results of measurements for the frequency range $800-900 \mathrm{MHz}$ and $1600-2200 \mathrm{MHz}$, the operator Telkomsel be an option as the network that will be used in connecting the data obtained from the sensor (RSU) to the central office server. Therefore, this research will be sought Telkomsel BTS sites near the road as the location of which will be placed sensors RSU

\subsection{Mapping Location of Measurement.}

Mapping Location of measurements were made using Google Earth software. It aims to determine the position of the existing base stations along the way. Because the client-server communication using the GPRS network so that the number and location of base stations greatly support the communication process.

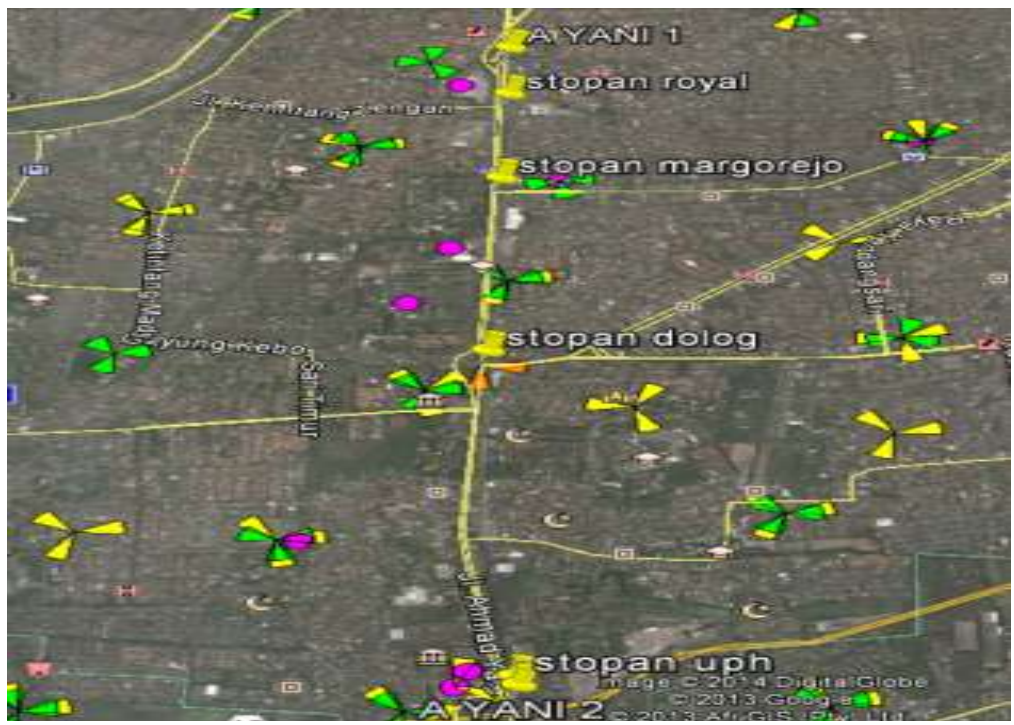

Figure 3: BTS Telkomsel at Ahmad Yani Street (Google Earth)

RSU selected for the installation location on the Surabaya Ahmad Yani street stretching from west to east. On the road there are few traffic lights that cause changes in the density and speed of the vehicle. On the street also has many corresponding BTS Telkomsel is used to create a network of interconnections between the RSU and the central office server. Data on the characteristics of the road can be seen in Table 3 [7]. In Figure 3 shows the base stations located along the Ahmad Yani street. Data Field Surveys and Mapping Google Earth as Figure 4 above is used to determine the placement of client infrastructure (sensor-ATMEGA 162-SIM 900) is based on the actual conditions that exist in the field. The accuracy of the infrastructure's client (sensors) and the existence of a good mobile network signal characterized by the BTS availability along the measuring point. It is a factor contributing to the success of infrastructure planning I2I communication system along the Ahmad Yani street.

Table 3: Data Ahmad Yani Street, Surabaya

\begin{tabular}{|l|l|}
\hline Lenght & $4,78 \mathrm{~km}$ \\
\hline Wide & $0,01 \mathrm{~km}$ \\
\hline Rute & Royal Plaza- Bundaran Waru \\
\hline A YANI 1 & $7^{\circ} 18^{\prime} 29.08^{\prime \prime} \mathrm{S} 112^{\circ} 44^{\prime} 8.68^{\prime \prime} \mathrm{E}$ \\
\hline A YANI 2 & $7^{\circ} 20^{\prime} 46.19^{\prime \prime} \mathrm{S} 112^{\circ} 43^{\prime} 45.46^{\prime \prime} \mathrm{E}$ \\
\hline Category & Urban \\
\hline Average velocity & $35 \mathrm{~km} / \mathrm{h}$ \\
\hline Time & $8,06 \mathrm{menit}$ (no delay) \\
\hline
\end{tabular}




\subsection{Link Budget Calculation}

Technical data Telkomsel 2G base stations located along the Ahmad Yani street[8] is used as primary data in a communication system link budget calculation. From the data, It have known 8 tower BTS (GSM and GPRS), 2 BTS tower has two antennas with the GSM and GPRS systems in one tower. Longitude and latitude BTS were used to determine the actual position. GSM and GPRS systems on the antenna used to determine the link budget calculation models in the BTS. For the GSM system (900 MHz) used the calculation model Okumura Hata while for GPRS (1800 $\mathrm{MHz}$ ) used the calculation model extended Hata or better known as the Cost 231 Hata. Antenna height is one of the important parameters in the link budget calculation. From the data obtained through the Telkomsel BTS data analysis along the Ahmad Yani street and field surveys, the data obtained along with the number of Traffic Light nearest BTS. Selection of two Traffic Light for the placement of the sensors during field data collection, based on parameters of the vehicle density central location near several major intersections as well as the existence of a nearby base stations that can reach out to the server ITS, as shown in Table 4

Table 4 : The nearest BTS at Ahmad Yani Street

\begin{tabular}{|c|c|c|}
\hline BTS Traffic Light Margorejo & Longitude & Latitude \\
\hline GIANTHYPERMARKETMG3 & 112.7362 & -7.316 \\
\hline IAINMG3 & 112.7334 & -7.32215 \\
\hline IAINMD2 & 112.7334 & -7.32215 \\
\hline BTS Traffic Light Uph & Longitude & Latitude \\
\hline CITYOFTOMMOROWMD2 & 112.7278 & -7.3451 \\
\hline SRIKANDIMD1 & 112.7261 & -7.34608 \\
\hline SRIKANDIMG1 & 112.726 & -7.34608 \\
\hline
\end{tabular}

Link budget calculation to determine the level of the signal received at the receiving antenna and its value must be greater than the sensitivity of the receiving device (RSL> Rth). It is used to analyze the condition of the transmission channel of communication signals from sensors on the highway to the server.

In the pathloss calculation used two models and Okumura Hata and COS 231.[10] Okumura Hata pathloss models predict median pathloss in three different environments, namely urban, suburban, and rural with equation (1) as follows

$$
L p=69.55+26.16 \log _{10}(f)-13.82 \log _{10}(h b)-a(h m)+\left(44.9-6.55 \log _{10}(h b)\right) \log _{10}(d)
$$

Cost 231 so-called Extended Okumura Hata as a development of Okumura Hata system that can cover the frequency range 1500 to $2000 \mathrm{MHz}$ with equation (2)

$$
L p=69.55+26.16 \log _{10}(f)-13.82 \log _{10}(h b)-a(h m)+\left(44.9-6.55 \log _{10}(h b)\right) \log _{10}(d)+C m(d b)
$$

Where $\quad a h m=\left[1.1 \log _{10}(f)-0.7\right] h m-\left[1.56 \log _{10}(f)-0.8\right], \mathrm{f}$ depend on the operator's frequency, $h b$ is BTS antenna height, $\mathrm{hm}$ is mobile antenna height, $d$ is distance between MS and BTS, and $\mathrm{Cm}$ is correction factor for COST 231-Hata model.

By combining the data obtained from the operator and the field survey pathloss value can be calculated based on height differences transmitting antenna and the surrounding environment as shown in Figure 4 and Figure 5

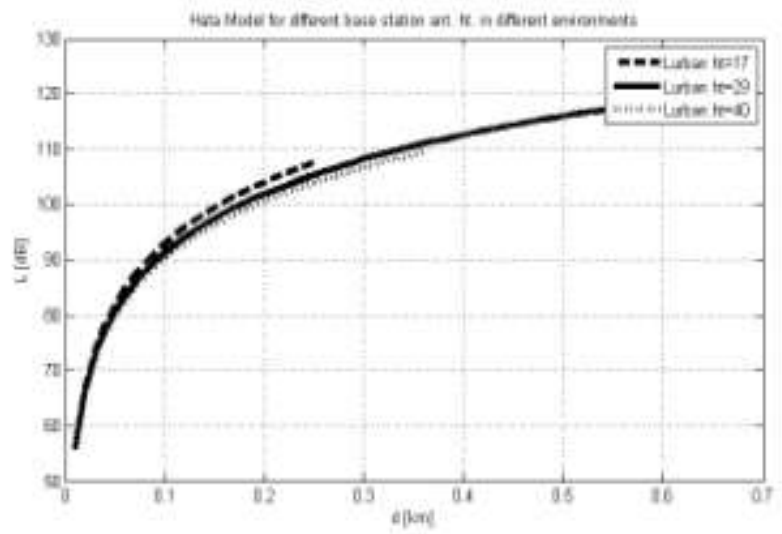

Figure 4: Pathloss urban area with Okumura Hata $\mathrm{f}=900 \mathrm{MHz}$ 
In Figure 4 showed that the higher the BTS, generated pathloss getting smaller. The better the signal transmission if the BTS antenna getting higher. Pathloss measurement methods Okumura Hata suited implemented in the GSM 900 and DCS $1800 \mathrm{MHz}$ for measurements in urban areas such as Ahmad Yani street Surabaya, which has a dense settlement, with a high traffic volume

\section{THE ROADSIDE UNIT SENSOR}

This study used the sensor counter the number of cars complete with the ability to detect the type of vehicle. In Table 5 obtained information that the sensor has two different operating modes, tracking and counting [9]. Tracking mode is used to display speed, vehicle speed warning system that goes beyond the limits of the measuring range far and wide.

Table 5: Sensor Specification

\begin{tabular}{|l|l|}
\hline \multicolumn{1}{|c|}{ Sensor Parameter } & \multicolumn{1}{c|}{ Standard } \\
\hline Antenna & Spear beam patch antenna \\
\hline Antenna beam width $(3 \mathrm{~dB})$ & $11^{\circ}$ x $11^{\circ}$ \\
\hline Measurement principle & Doppler - Radar \\
\hline Radar frequency & $24,165 \mathrm{GHz}, \mathrm{K}-$ Band \\
\hline Power Output & $5 \mathrm{~mW}(100 \mathrm{~mW}$ EIRP) \\
\hline Detection distance range & 150 meter \\
\hline Interface & RS 232 \\
\hline Data transmission rates & $\begin{array}{l}1200,2400,4800,9600,19200,57600 \\
\text { bps }\end{array}$ \\
\hline Operating mode & Counting and tracking \\
\hline Antenna & Spear beam patch antenna \\
\hline
\end{tabular}

The detector can detect vehicle speed for the vehicle to be in range radar sensor. In the counting mode detector can detect speed, vehicle classification, as well as the time gap between their vehicles. The time value out when the vehicle were passing the sensor. The best counting mode measurements at the closest distance to the object which being measured and the angle of 45 degrees to the side of the road (vertical / horizontal). The sensor has the capability of measuring distances up to $150 \mathrm{~m}$, and the parameters used to control the spacing is SENS, where the greater the measured value SENS greater distance, otherwise the smaller the value SENS measured distance is getting shorter. SENS were values between 1-16. The speed can be measured in the range of 1-255 km / h. The parameters were used to control the speed are ADJO and ADJL for incoming and outgoing, to measure vehicle speed separately for each direction of movement of the vehicle speed. In addition sensors can also detect the type and number of vehicles sector in the road. Detection capabilities reach 1-65535 vehicles.

\section{NETWORKS INTERCONNECTING MEASUREMEMT}

At the time of measuring interconnection between networks, systems should be implemented as in Figure 7 . The sensor is connected with the ATMEGA 162 and SIM 900 as client infrastructure and placed on the roadside to capture data related to the vehicle (speed, type, volume) on the traffic conditions. Then the data that has been compiled by Infrastructure client sent to the server via the GPRS network. On the server side there is a laptop that is connected to the Internet network where there are applications that can display and store the results of detection sensors automatically in the database.

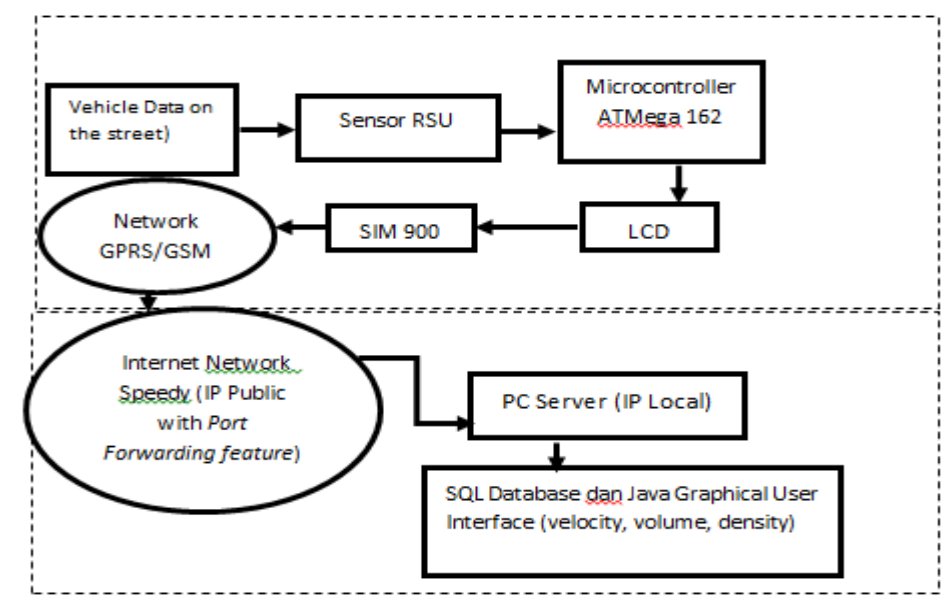

Figure 5: Block Diagram of System Implementation 


\subsection{Wireless Modem Initialization}

Because the condition gateway operator in the private status, so that the system needed port forwarding to connect to the communications network operator. Then designed port forwarding through the Internet (speedy) PENS by accessing the IP 121.225.2.112 Private Servers that have ports 9200 and 80 through PENS Public IP 103.24.59.3(Figure 6). The result Client-Server can communicate even send data through port 80 by activating the xampp server on the server side (status: Connect OK). However, in port 9200is still not connected it is because applications that use TCP Test Tool less appropriate. Then conducted experiments using various TCP Socket tools and the results obtained by using TCP / IP Builder can be connected.

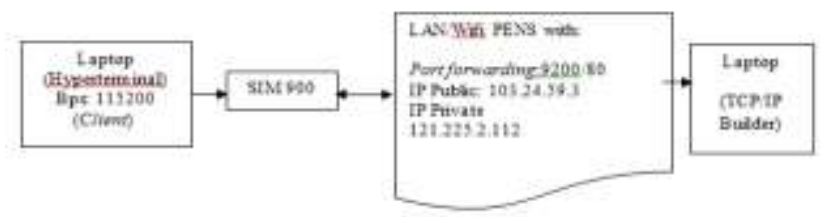

Figure 6: SIM 900 and PC configuration with port forwarding

\section{Data transmission based on TCP / IP through a network of Internet}

Communication between SIM 900 and the server is done with various trials. One of these data delivery network utilizing the Internet through a modem ADSL (Speedy) for connection on the server side, while the client still uses a GSM modem. On the server side TCP Test Tool software is used to monitor if no data is sent from the client or not, while on the client side to use the data transmission with SIM900 GSM / GPRS Evaluation Kit through hyperterminal. This is to ensure data on the number of vehicles side of the road can be sent to a server that is in a particular place through the internet network (speedy) as seen in Figure 7.

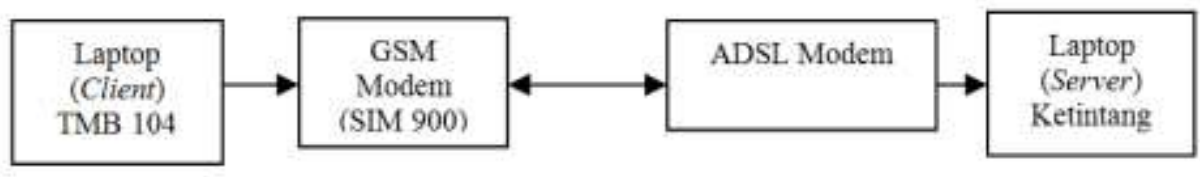

Figure 7: Topology data transmission through the Internet

On the client side, setting the hyperterminal used for sending data to the server with a baud rate of $112500 \mathrm{bps}$. To determine the signal strength during the initialization process of transmitting data is performed beginning with the command AT + CSQ. As for checking the connection requires a password or not given the command AT + CPIN, if the result is READY, the connection can be done. Data transmission is done using the provider XL so given the command $\mathrm{AT}+\mathrm{CSTT}=$ "XL" for setting the APN. Terminal configuration on the "client" is obtained from the command AT + CIICR used to connect to the GPRS network. Followed by the command AT + CIFSR to get local ip address. To initiate a TCP connection to the server is used command AT + CIPSTART = "TCP", "public IP server", "port forwarding". If it gets the response CONNECT OK means successful connection to the server and data transfer can be done. IP 36.82.81.112 given a public ip server on the Internet (Speedy), whereas in 1234 the port forwarding port forwarding that has been set before the modem TP-LINK

On the server side, first performed ADSL modem settings to create a port forwarding. To arrange the port forwarding on the ADSL modem, it have done at setup NAT (Network Address Translation). Used in this project forwarding port number "1234" for the local IP "192.168.1.3" so that when a client connects to the server via public IP addresses owned by the ADSL modem will be transferred to the local IP (192.168.1.3). After the PC server running the software TCP Test Tool, while. On the client side, the software used hyperterminal to send AT Command via the SIM 900.

\section{Communication AT MEGA 162 to SIM900}

In the serial communication between the microcontroller AT Mega 162 and SIM 900 to the laptop, the SMS delivery simulation with the following configuration:

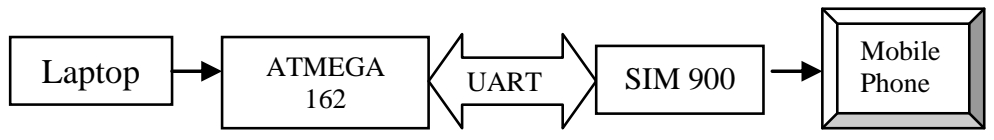

Figure 8: ATMega162 UART communication with SIM900

Previously, checking the network by sending sms via a microcontroller , the configuration show in Figure 9 . In the TX-RX port B is connected to the TX-RX-Ground Neo SIM GSM 900 (UART) by connect a jumper on the J8 and J9 as 
TTL UART interface. In the process of integration of the overall system as shown in Figure 11, so that the micro SIM AT Mega 900 and 162 can receive power supply independently and can work properly during a series of measurements then added $11.1 \mathrm{~V}$ battery, $5200 \mathrm{~mA}$. The value of current correlated with the life time of the battery. These batteries are divided into two branches, one branch is connected to the SIM 900 and the other branch is connected to the AT Mega 162 (5V). At Micro Port B is connected in sensor, while Port D is connected to the SIM 900.

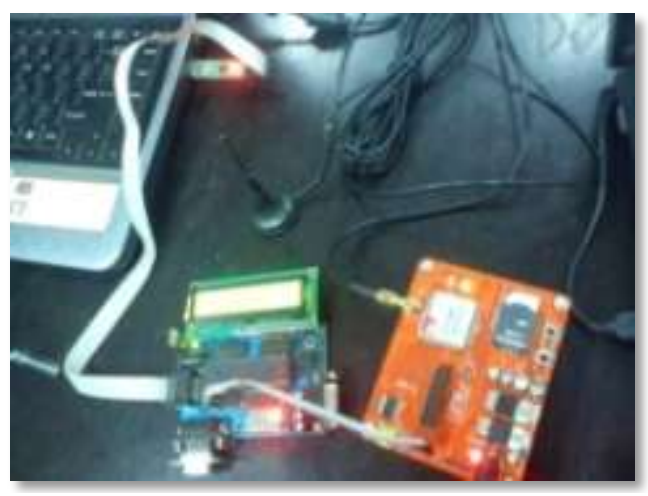

Figure 9: Pengiriman sms melalui mikrokontroler

\subsection{Sensor Initialization (Counting Mode)}

The sensor has two kinds of operating modes, namely Counting and Tracking. For Counting mode, data on the number of vehicles that pass through a wide range of radar, the data include speed, profile / classification of vehicles, and the gap / time between vehicles. The value obtained from each passing vehicle, vehicle speed data is sent when a vehicle enters the radar beam, while for the data profile / classification of the vehicle as well as its gap width is obtained when the vehicle passes the radar. Use standard angle is 45 degrees facing the measured object. The detector works on two types, unidirectional (one direction) or bidirectional (two-way). The value of the vehicle speed away / the opposite direction of the sensor always (-) negative. The maximum distance that can be detected is $150 \mathrm{~m}$. Distance range depends on the setting of parameter SENS. Sensor have two variables ADJO and ADJL for traffic coming and going in measuring the value of vehicle speed. Tracking mode is generally used under the measurement angle of 10 degrees to achieve maximum distance range to display the vehicle speed data and the rate of a vehicle speed limit warning system. For standard counting mode ADJO (ADJL) used is 1296 (1572).

Vehicle detection process ends with the loss of Doppler signal in each period. The length of time for each period is $10 \mathrm{~ms}$. GAPL is a multiplier for a minimum timeout interval. Period timeout = GAPL * 10 ms. Counting mode GAPL to be set between 8-15 to identify every passing vehicle. If the GAPL value is too small, the truck will be recognized as two different vehicles, if too large, then the vehicle will be recognized as a major vehicle. At GAPL Tracking mode is generally set to 100 , every second to address the multiple detection of a range of distance measurement.

Table 6: Angle Sensor Parameter Test Results

\begin{tabular}{|l|l|l|l|}
\hline No. & Angle & \multicolumn{1}{|c|}{ Motorcycles } & \multicolumn{1}{|c|}{ Cars } \\
\hline 1 & $0-20$ & $\begin{array}{l}\text { Accurate data / valid } \\
\text { appropriate vehicle } \\
\text { classification table }\end{array}$ & $\begin{array}{l}\text { Data is not accurate (not } \\
\text { according to the table } \\
\text { classification standards of } \\
\text { vehicles) }\end{array}$ \\
\hline 2 & $25-40$ & Accurate data / valid & $\begin{array}{l}\text { The data came partially } \\
\text { true (according to the } \\
\text { classification table), others } \\
\text { wrong data / valid }\end{array}$ \\
\hline 3 & $45-60$ & Accurate data / valid & $\begin{array}{l}\text { Accurate data } \\
\text { appropriate } \\
\text { classification table }\end{array}$ \\
\hline 4 & $65-80$ & $\begin{array}{l}\text { Accurate data / valid, } \\
\text { value <180 }\end{array}$ & $\begin{array}{l}\text { Data is not accurate, value } \\
<180\end{array}$ \\
\hline 5 & $85-90$ & $\begin{array}{l}\text { Data rarely appear, } \\
\text { accurate }\end{array}$ & $\begin{array}{l}\text { Data rarely appear, not } \\
\text { accurate }\end{array}$ \\
\hline
\end{tabular}

For Counting mode, the output gap data can be activated with toogle switch IVG. And the time span between 0.01-655.3 seconds. Net time gap can be used to calculate occupancy of a road / path or distance between vehicles. 
Display data output when the vehicle passes through the sensors include speed; profile; gap. Speed limit 0-255 km / h while the profile contains the type of vehicles consisting of 3 categories (motorcycles, buses, and cars), while for the gap is the time starting from the arrival of the vehicle with the next one. Sensor settings affect the angle of the output value of the vehicle so that it will affect the determination of the classification of vehicles. Setting the best angle that between 45- $60^{\circ}$ angle, because the angle range the sensor can detect vehicles, both Motorcycle and Car accurately. Results of testing the angle and height of installation of the sensor can be seen in table 6 and 7

Table 7: Test Results with Parameter Height Sensor (on the side road)

\begin{tabular}{|l|c|l|}
\hline No. & Height & \multicolumn{1}{c|}{ Result } \\
\hline 1 & $40-120 \mathrm{~cm}$ & $\begin{array}{l}\text { High position with the most Cars and motor } \\
\text { can be measured with accurate / valid }\end{array}$ \\
\hline 2 & $105 \mathrm{~cm}$ & $\begin{array}{l}\text { Car is invalid } \\
\text { Motor measurable valid }\end{array}$ \\
\hline 3 & $105-150 \mathrm{~cm}$ & $\begin{array}{l}\text { Cars are not measurable accurate / valid } \\
\text { Motor measurable valid }\end{array}$ \\
\hline
\end{tabular}

Table 8: Results Calculation of GAP error percentage

\begin{tabular}{|c|c|c|c|}
\hline \multirow{2}{*}{$\begin{array}{c}\text { Vehicles } \\
\text { Data }\end{array}$} & \multicolumn{2}{|c|}{ GAP (detik) } & Error \\
\cline { 2 - 3 } & Handphone & Hyperterminal & Percentage(\%) \\
\hline 1 & 2,7 & 2,85 & 1,85 \\
\hline 2 & 5,6 & 5,64 & 0,71 \\
\hline 3 & 2,41 & 2,4 & 0,41 \\
\hline 4 & 5 & 4,55 & 1 \\
\hline 5 & 3,8 & 3,74 & 1,57 \\
\hline
\end{tabular}

From the results of test measurements with the parameters of height sensors on the side of the road as shown in Table 7 obtained the best measurement results at a height of 40-120 cm from ground level. Meanwhile, if placed on the overpass / crossing where the position sensor is directly facing the highway to be reached, the sensor can be placed at a height of 5-6 m from ground level. GAP value is the time starting from the arrival of the vehicle at the next vehicle, calculated on two different devices, namely mobile phones and Hyperterminal (Laptop).The output gap shown by the sensor and received in hyperterminal almost equal to the output at the time of calculation directly using mobile phones, with the average percentage error of less than $2 \%$, which means that the accuracy of measurements with these sensors is almost perfectly fits the actual data field (Table 8).

\subsection{Testing Delivery Vehicle Data on Wireless Channel}

This test is performed to determine whether the vehicle data can be sent from RSU on wireless channel to the server computer. Vehicle data transmission method that is based on TCP / IP and SMS gateway. Location of Road Side Unit (RSU) in the vicinity of Ahmad Yani Street, Darmo Street, and Merr Ringroad. Ahmad Yani street and Darmo street grouped in urban areas because it is located in a densely populated residential area and both main streets in Surabaya, while road Merr grouped in sub-urban areas because of its location in a residential area that is not too dense. Location Server namely the Road New Ketintang II A No. 15A. Data test results are shown in Table 9.

Table 9: The test results data transmission on wireless channels

\begin{tabular}{|c|c|c|c|c|c|}
\hline \multirow{2}{*}{ No } & $\begin{array}{c}\text { RSU } \\
\text { Location }\end{array}$ & $\begin{array}{l}\text { RSU } \\
\text { Locate }\end{array}$ & \multicolumn{2}{|c|}{$\begin{array}{c}\text { RSU - } \\
\text { Server } \\
\text { Distance }\end{array}$} & \multicolumn{2}{|c|}{$\begin{array}{c}\text { Data } \\
\text { Transmission } \\
\text { status }\end{array}$} \\
\cline { 5 - 6 } & Success & Fail \\
\hline 1 & $\begin{array}{c}\text { Ahmad } \\
\text { Yani St }\end{array}$ & Urban Area & $\pm 4 \mathrm{~km}$ & $\sqrt{ }$ & \\
\hline 2 & $\begin{array}{c}\text { Merr } \\
\text { Ringroad }\end{array}$ & $\begin{array}{c}\text { Sub-Urban } \\
\text { Area }\end{array}$ & $\pm 12 \mathrm{~km}$ & $\sqrt{ }$ & \\
\hline 3 & $\begin{array}{c}\text { Darmo } \\
\text { Street }\end{array}$ & Urban Area & $\pm 3 \mathrm{~km}$ & $\sqrt{ }$ & \\
\hline
\end{tabular}

Based on the results of previous testing, it is known that the vehicle data successfully transmitted from RSU placed in the area Ahmad Yani street, Merr Ringroad and Raya Darmo street to servers located in Ketintang Baru Street II A No. 15A. Of all sample data transmitted, the location of the placement of the RS area of urban and sub-urban as well as distance data transmission from RSU to the server is not a problem in data transmission vehicle. All data has been received on the server computer, see table 10. From this test it can be concluded that the wireless channel can be used as a medium for data transmission from the server to the RSU in urban areas as well as in the sub-urban areas. 
Table 10: Data Transmission Based on TCP / IP with a Height of $90 \mathrm{~cm}$ and the Angle Orientation of Sensor $45^{\circ}$

\begin{tabular}{|c|c|c|c|c|}
\hline No & Text Transmitted & Text Received & Succes & Character \\
\hline 1 & $\begin{array}{l}\text { Selamat Pengiriman } \\
\text { Berhasil }\end{array}$ & $\begin{array}{l}\text { Selamat Pengiriman } \\
\text { Berhasil }\end{array}$ & $\sqrt{ }$ & 25 \\
\hline 2 & $\begin{array}{l}\text { Pengiriman Data kecepatan } \\
\text { kendaraan dengan } \\
\text { mikrokontroler ATmega } \\
162 \text { berbasis jaringan } \\
\text { GSM/GPRS berbasis } \\
\text { TCP/IP di jalan Tol }\end{array}$ & $\begin{array}{l}\text { Pengiriman Data kecepatan } \\
\text { kendaraan dengan } \\
\text { mikrokontroler ATmega } 162 \\
\text { berbasis jaringan } \\
\text { GSM/GPRS berbasis } \\
\text { TCP/IP di jalan Tol }\end{array}$ & $\sqrt{ }$ & 127 \\
\hline 3 & !@\#\$\%^\&*()_+<>?:"'\{\} & !@\#\$\%^\&*()+<>?:" \{\} & $\sqrt{ }$ & 19 \\
\hline 4 & 1234567890 & 1234567890 & $\sqrt{ }$ & 10 \\
\hline 5 & Penelitian\#hibah\#di\#pens & Penelitian\#hibah\#di\#pens & $\sqrt{ }$ & 24 \\
\hline 6 & $\begin{array}{l}\text { Intelligent\$ } \\
\text { Transportation } \$ \text { System }\end{array}$ & $\begin{array}{l}\text { Intelligent\$ } \\
\text { Transportation\$System }\end{array}$ & $\sqrt{ }$ & 33 \\
\hline
\end{tabular}

Table 11: Time delay of data transmission from RSU to Server

\begin{tabular}{|c|c|c|c|}
\hline \multirow{2}{*}{ Event } & \multicolumn{3}{|c|}{ Time Delay with varying Condition (second) } \\
\cline { 2 - 4 } & Morning & Afternoon & Evening \\
\hline 1 & 1.21 & 1.18 & 1.15 \\
\hline 2 & 1.04 & 1.26 & 1.27 \\
\hline 3 & 1.12 & 1.15 & 0.98 \\
\hline 4 & 0.97 & 1.07 & 1.02 \\
\hline 5 & 1.14 & 1.27 & 0.89 \\
\hline 6 & 0.89 & 0.96 & 1.24 \\
\hline 7 & 0.97 & 1.02 & 1.35 \\
\hline 8 & 1.17 & 1.12 & 1.04 \\
\hline 9 & 1.05 & 1.37 & 0.88 \\
\hline 10 & 1.21 & 0.85 & 0.92 \\
\hline 11 & 0.84 & 1.09 & 0.84 \\
\hline 12 & 0.93 & 1.15 & 1.02 \\
\hline 13 & 1.05 & 1.17 & 0.85 \\
\hline 14 & 0.86 & 1.27 & 0.97 \\
\hline 15 & 0.95 & 0.95 & 1.08 \\
\hline AVRG & 1.05 & 1.13 & 1.03 \\
\hline
\end{tabular}

Delay time measurements performed several times at different times of measurement to ensure the condition of the network used to transmit data from roadside sensors (RSU) to the server. Based on the measurement table 11 showed that an average of about 1 second. Wireless channel can be used as a medium for data transmission from Roadside Unit (RSU) side of the highway to the server at the location of urban and sub-urban. Type the location and distance of data transmission from the server to the RSU is not a problem in the process of sending data. The Data could be delivered with through the GPRS network because the maximum capacity of each vehicle data sent is 128 bytes, while the data transmission capabilities to the SIM 900 reach $85.6 \mathrm{Kbps}$ to $42.8 \mathrm{Kbps}$ for downlink and uplink. Time Delay required for data transmission on all samples only 1 second so that it can be concluded from the data transmission from RSU toward server in the wireless channel is success.

\section{ACKNOWLEDGEMENT}

Thanks to my colleague and member of microwave laboratory who have contributed to the success of this research. The author also wishes to thank to DP2M DIKTI that has funded research through grant competition in $2014-2015$.

\section{REFERENCES}

[1] K. Kishimoto, M. Yamada, M. Jinno, “ Cooperative Inter-Insfrastructure Communication System Using $700 \mathrm{MHz}$ Band, SEI Technical review, Number 78, April 2014

[2] M. Shahid A, Chris Guy, A Survey of VANET Technology, Journal of Emerging Trend in Computing and Information Sciences, Vol. 5, 9 September 2014 
[3] B.Aslam, F.Amjad and C.C. Zou,“Optimal Roadside Units Placement in Urban Areas for Vehicular Networks"Proceedings of ICSS 2012, (2012),pp.423-429

[4] Pavle Belanovic', Thomas Zemen, On Wireless Links for Vehicle-to-Infrastructure Communications, IEEE Transactions on Vehicular Technology, Vol59, Issue:1, pp269-282, 2010.

[5] Nur Adi S, Okkie P, Ari W, Analysis of Area Environmental Conditions in Surabaya to Support The Communication System of ITS, The Third Indonesian-Japanese Conference on Knowledge Creation and Intelligent Computing (KCIC), March 25-26, Malang, Indonesia, 2014.

[6] Setiawan, Denny.. Alokasi Frekuensi: Kebijakan dan Perencanaan Spektrum Indonesia. Depkominfo Dirjen Postel, 2010 Jakarta.

[7] Prastiyono, Hendri. Penentuan Jalur Alternatif Transportasi sebagai upaya mengurangi kemacetan di jalan raya ahmad yani surabaya. Pendidikan Geografi, UNESA

[8] Data teknis BTS Telkomsel 2G, Huawei 2011

[9] Viatraffic.2013. Manual Digital Falcon Plus II. Leverkusen,Germany.

[10] Mecklenbrauker, C.F., et all., Vehicular channel characterization and its implications or wireless system design and performance, Proc. IEEE 99(7), pp. 1199-1212, 2011 